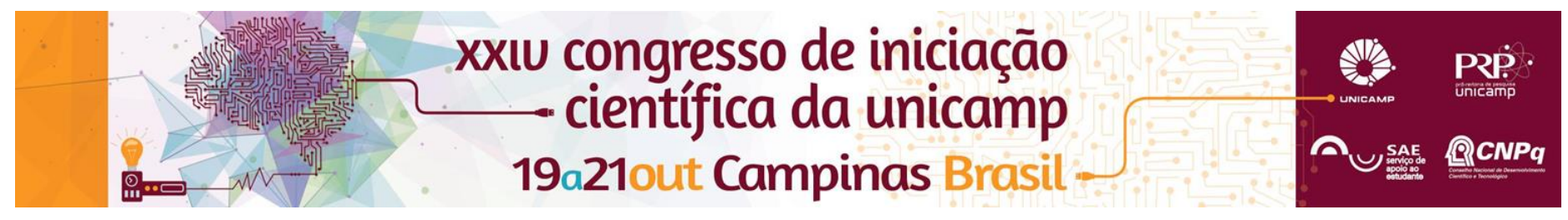

\title{
O CONHECIMENTO DOS ENFERMEIROS SOBRE MEDICAMENTOS DE ALTA VIGILÂNCIA
}

\author{
Amanda Cristina Cocco*, Maria Helena Melo Lima, Priscila Peruzzo Apolinario
}

\section{Resumo}

Os medicamentos de alta vigilância (MAV) tem maior risco de causar danos graves ao paciente em caso de erros durante seu uso. Objetivo: avaliar o conhecimento de enfermeiros sobre os MAV por meio do questionário Conhecimento de enfermeiros sobre os MAV. Método: estudo transversal, realizado em um hospital universitário, com 84 enfermeiros de unidades de internação e terapia intensiva. Resultados: predomínio do sexo feminino, elevada experiência e tempo de trabalho, com maiores escores na regulamentação dos medicamentos do que na administração, o que sugere que a experiência com a pratica profissional agrega saberes sobre a regulamentação dos MAV. Os enfermeiros que receberam treinamento sobre os MAV obtiveram menor escore do que o grupo que não recebeu. Conclusão: os dados reforçam a necessidade de treinamentos adequados sobre os MAV, com ênfase na administração dos medicamentos.

Palavras-chave: Enfermagem; Medicamentos de Alta Vigilância; Erros de medicação.

\section{Introdução}

Os MAV apresentam um maior risco de causar danos significativos ao paciente quando um erro ocorre durante sua utilização ${ }^{1}$. Sabendo que a equipe de enfermagem, sob a responsabilidade do enfermeiro, possui o dever legal da administração de medicamentos, e que na associação de erros de medicação com os MAV, temos então a importância da avaliação do conhecimento dos enfermeiros a respeito de tais medicamentos ${ }^{2}$. Assim, o Objetivo deste estudo foi verificar o conhecimento dos enfermeiros sobre os MAV por meio do questionário Conhecimento de enfermeiros sobre Medicamentos de Alta Vigilância (Q-CEMAV) ${ }^{3}$. Trata-se de estudo transversal realizado em um hospital universitário com 84 enfermeiros assistenciais. Foram analisados os escores de pontuação, onde o maior escore indica maior conhecimento e o menor escore indica menor conhecimento dos enfermeiros sobre os $\mathrm{MAV}^{3}$. Os dados da pesquisa foram analisados por meio de análise descritiva e inferencial.

\section{Resultados e Discussão}

Participaram desse estudo 84 enfermeiros, com predomínio do sexo feminino e elevada experiência e tempo de trabalho na Instituição, conforme a tabela 1 que apresenta as características gerais da população.

Tabela 1 - Características gerais da população de 84 enfermeiros Campinas, SP, Brasil, 2016

\begin{tabular}{lc} 
Caracteristicas & $\mathbf{N}=\mathbf{8 4}$ \\
Idade (anos) $*$ & $37,85(\mathrm{DP}=7,82)$ \\
Sexo (feminino) & $84,52 \%$ \\
Lato sensu completo & $63,10 \%$ \\
Strictu sensu completo & $11,90 \%$ \\
Tempo de trabalho na instituição (anos) $*$ & $10,98(\mathrm{DP}=8,44)$ \\
Experiência (anos) * & $12,4(\mathrm{DP}=8,1)$ \\
Unidade de atuação & \\
$\quad$ Unidade Terapia Intensiva & $76,19 \%$ \\
$\quad$ Unidades de internação & $23,81 \%$ \\
Treinamento admissional & $89,29 \%$ \\
Treinamento sobre MAV & $25,00 \%$ \\
\hline
\end{tabular}

Valores descritos em porcentagem; *Média (DV)

Dos respondentes, $56 \%$ obteve de 70 a $89 \%$ de acerto, $31 \%$ obteve até $70 \%$ de acerto e apenas $13 \%$ obteve mais que $90 \%$ de acerto. A tabela 2 nos mostra as médias das pontuações obtidas pelos participantes. Com o teste de Mann-Whitney, vimos que há correlação entre as variáveis escore total, escore parte A e escore parte $B$ com o grupo Treinamento MAV. Pelo coeficiente de correlação de Spearmam não foram encontradas correlações com nível de significância entre as diferentes variáveis.

Tabela 2 - Média de Pontuação e Desvio Padrão segundo a especialização e treinamento sobre os MAV. Campinas, SP, Brasil, 2016. *Média (DP)

\begin{tabular}{ccccc}
\hline Grupo de sujeitos & $\mathbf{n}(\%)$ & $\begin{array}{l}\text { Escore } \\
\text { Parte A* }\end{array}$ & $\begin{array}{c}\text { Escore } \\
\text { Parte B* }\end{array}$ & $\begin{array}{c}\text { Escore } \\
\text { total* }\end{array}$ \\
\hline Lato sensu & 53 & 44,62 & 42,45 & 87,08 \\
completo & $(63,10 \%)$ & $(9,19)$ & $(8,80)$ & $(13,50)$ \\
Strictu sensu & 10 & 46,00 & 44,50 & 90,50 \\
completo & $(11,90 \%)$ & $(9,07)$ & $(7,98)$ & $(11,17)$ \\
Treinamento & 21 & 40,71 & 39,05 & 79,76 \\
MAV & $(25,61 \%)$ & $(9,39)$ & $(7,00)$ & $(12,60)$ \\
Total geral de & 84 & 44,35 & 42,62 & 86,96 \\
sujeitos & $(100 \%)$ & $(8,70)$ & $(7,93)$ & $(12,75)$ \\
\hline
\end{tabular}

\section{Conclusão}

Os dados sugerem que o elevado tempo de experiência profissional, e trabalho na instituição associado com a especialização Lato sensu completa teve um maior impacto nas pontuações comparado com quem recebeu treinamento sobre os MAV. Os enfermeiros apresentam maior conhecimento sobre a regulamentação dos medicamentos do que administração, o que sugere que a experiência dos enfermeiros mais a prática profissional agrega saberes sobre a regulamentação. Os resultados confirmam os dados da literatura sobre a necessidade de treinamento qualificado sobre os MAV, com ênfase nos conhecimentos teóricos sobre administração de medicamentos, para obter melhores resultados.

\section{Agradecimentos}

\section{QCNPq}

1-Instituto para Práticas Seguras no uso de Medicamentos (ISMP-Brasil) Medicamentos Potencialmente Perigosos [Internet]. Belo Horizonte: ISMP [acessado em 08 de março 2015].

2-Lu MC, Yu S, Chen IJ, Wang KWK, Wu HF, Tang FI. Nurses' knowledge of highalert medications: a randomized controlled trial. Nurse Educ Today. $2011 \mathrm{Dec}$ 15 .

3-Apolinario PP, Rodrigues RCM, Silva JB, Secoli SR, Lima MHM. Tradução, adaptação e praticabilidade do Nurses' knowledge of high alert medications para a cultura brasileira. Rev. Eletr. Enf. [Internet]. 2015 jul./set.;17(3) 